\title{
Segregation and Convergence of Information Flow through the Cortico-Subthalamic Pathways
}

\author{
B. P. Kolomiets, ${ }^{1}$ J. M. Deniau, ${ }^{1}$ P. Mailly, ${ }^{2}$ A. Ménétrey, ${ }^{1}$ J. Glowinski, ${ }^{1}$ and A. M. Thierry ${ }^{1}$ \\ 1/nstitut National de la Santé et de la Recherche Médicale U114, Chaire de Neuropharmacologie, Collège de France, \\ 75231 Paris Cedex 05, France, and 2NPA-NSI, Centre National de la Recherche Scientifique, Université Pierre et Marie \\ Curie, 75230 Paris Cedex 05, France
}

Cortico-basal ganglia circuits are organized in parallel channels. Information flow from functionally distinct cortical areas remains segregated within the striatum and through its direct projections to basal ganglia output structures. Whether such a segregation is maintained in trans-subthalamic circuits is still questioned. The effects of electrical stimulation of prefrontal, motor, and auditory cortex were analyzed in the subthalamic nucleus as well as in the striatum of anesthetized rats. In the striatum, cells $(n=300)$ presenting an excitatory response to stimulation of these cortical areas were located in distinct striatal territories, and none of the cells responded to two cortical stimulation sites. In the subthalamic nucleus, both prefrontal and motor cortex stimulations induced early and late excitatory responses as a result of activation of the direct cortico-subthalamic pathway and of the indirect cortico-striatopallido-subthalamic pathway, respectively. Stimulation of the

The striatum and the subthalamic nucleus (STN) are the two main structures through which cortical signals are transmitted to the output nuclei of the basal ganglia, i.e., the substantia nigra pars reticulata $(\mathrm{SNR})$ and the internal segment of the globus pallidus (GPi) (Albin et al., 1989). Both the striatum and the STN receive direct excitatory inputs from the cerebral cortex. Through its direct GABAergic projections, the striatum exerts an inhibitory influence on the SNR and the GPi whereas, via its glutamatergic projection neurons, the STN provides a major excitatory drive to these structures (Kitai and Kita, 1987; Smith et al., 1998). The STN also receives cortical information through a multisynaptic circuit involving the striatum and the external segment of the globus pallidus (GPe) (Albin et al., 1989, Smith et al., 1998). Via this indirect circuit, the cerebral cortex activates the STN through a disinhibitory process (Maurice et al., 1998). Thus, the direct striatal inputs and the trans-subthalamic pathways exert opposite effects on the output structures of the basal ganglia (Maurice et al., 1999; Nambu et al., 2000).

Supporting the concept that cortico-basal ganglia circuits are organized in parallel channels, growing evidence indicates that

Received Feb. 26, 2001; revised May 4, 2001; accepted May 11, 2001.

This work was supported by Institut National de la Santé et de la Recherche Médicale. B. K. is a recipient of a fellowship from the Ministère de l'Education Nationale, de la Recherche et de la Technologie. We thank S. Slaght for critical reading of the manuscript and A. M. Godeheu and M. Saffroy for histological assistance.

Correspondence should be addressed to Anne-Marie Thierry, Institut National de la Santé et de la Recherche Médicale U114, Chaire de Neuropharmacologie, Collège de France, 11 place M. Berthelot, 75231 Paris Cedex 05, France. E-mail: anne-marie.thierry@college-de-france.fr.

Copyright (C) 2001 Society for Neuroscience 0270-6474/01/215764-09\$15.00/0 auditory cortex, which does not send direct projection to the subthalamic nucleus, induced only late excitatory responses. Among the subthalamic responding cells $(n=441)$, a few received both prefrontal and motor cortex $(n=19)$ or prefrontal and auditory cortex $(n=10)$ excitatory inputs, whereas a larger number of cells were activated from both motor and auditory cortices $(n=48)$. The data indicate that the segregation of cortical information flow originating from prefrontal, motor, and auditory cortices that occurred in the striatum is only partly maintained in the subthalamic nucleus. It can be proposed that the existence of specific patterns of convergence of information flow from these functionally distinct cortical areas in the subthalamic nucleus allows interactions between parallel channels.

Key words: prefrontal cortex; motor cortex; auditory cortex; striatum; subthalamus; basal ganglia; rat; ketamine

signals originating from functionally distinct cortical areas are processed in separate striatal territories and remain segregated in the direct striatopallidal and striatonigral pathways (Alexander al., 1986; Groenewegen and Berendse, 1994; Deniau and Thierry, 1997; Kitano et al., 1998). This organization in parallel circuits does not exclude the existence of convergence because each of these parallel circuits integrates cortical information originating from functionally related cortical areas (Yeterian and Van Hoesen, 1978; Flaherty and Graybiel, 1991; Deniau et al., 1996). Whether the principle of a parallel processing of information originating from functionally distinct cortical areas also applies to the transsubthalamic basal ganglia circuits remains to be established. Indeed, it has been shown that the direct cortical inputs to the STN only originate from the prefrontal and motor cortices and innervate the entire STN with a mediolateral topography (Afshapour, 1985; Canteras et al., 1990; Berendse and Groenewegen, 1991; Nambu et al., 1996). In addition, the indirect cortico-striatopallido-subthalamic pathways that are derived from the whole cerebral cortex also innervate the entire STN in a topographical manner (for review, see Joel and Weiner, 1997; Smith et al., 1998).

The aim of the present study was to determine to what extent the segregation of information flow from functionally distinct cortical areas that occurs in the striatum is also maintained within the STN. For this purpose, using anatomical and electrophysiological approaches, the organization of the projections to the striatum and the STN of three functionally distinct cortical areas [the prelimbicmedial orbital areas of the prefrontal cortex (PL-MO) and the orofacial-forelimb areas of the motor cortex and the auditory cortex] were analyzed in anesthetized rats. 


\section{MATERIALS AND METHODS}

Experiments were performed on 23 adult male Sprague Dawley rats (270-300 gm; Charles River, Saint Aubin-les-Elbeuf, France). Efforts were made to prevent animal suffering and to reduce the number of animals used.

Anatomical experiments. Before surgical procedure, animals were anesthetized by an initial injection of sodium pentobarbital $(40 \mathrm{mg} / \mathrm{kg}$, i.p.) that was supplemented by administration of ketamine $(30 \mathrm{mg} / \mathrm{kg}$, i.m.; Imalgène 500, Rhône-Mérieux, France). In four rats, microiontophoretic injections of wheat germ agglutinin conjugated with horseradish peroxidase (WGA-HRP; Sigma, St. Louis, MO; $2.5 \%$ in $0.9 \%$ saline) were performed within prefrontal [anterior (A), 12.5; lateral (L), 0.4 from the interaural line; height $(\mathrm{H}), 3.5 \mathrm{~mm}$ from the cortical surface], motor (orofacial area: A, 12.5; L, 3.8; H, 1.5; rostral forelimb area: A, 12; L, 2.3; $\mathrm{H}, 1.5)$, and auditory areas (A, 3.5; L, 7,2; H, 2) of the cerebral cortex, using glass micropipettes (internal tip diameter, $15 \mu \mathrm{m}$ ) and a iontophoretic delivery method (positive current pulses of $5 \mu \mathrm{A}$ for 5-15 min). After a survival period of 36-48 hr, the animals were deeply anesthetized with pentobarbital $(160 \mathrm{mg} / \mathrm{kg}$, i.p.) and perfused through the left ventricle with $100 \mathrm{ml}$ of $0.9 \%$ saline, $500 \mathrm{ml}$ of $3 \%$ glutaraldehyde in 0.1

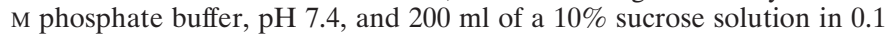
$\mathrm{M}$ phosphate buffer, $\mathrm{pH}$ 7.4. After dissection the brains were immersed in $10 \%$ sucrose phosphate buffer at $4^{\circ} \mathrm{C}$ until sectioned. Frozen sections were cut at $50 \mu \mathrm{m}$ and processed for HRP histochemistry using the tetramethylbenzidine method of Mesulam (1978). The sections were mounted onto chrome-alum-coated slides, counterstained with safranin, and dehydrated through alcohol to xylene for light microscopic examination.

The local diffusion of the marker, the distribution of retrogradely labeled cells within the thalamus as well as anterograde and retrograde labeling of cortico-cortical connections were analyzed with bright- and dark-field microscopy and reconstructed using a camera lucida.

Electrophysiological experiments. Electrophysiological experiments were performed in 19 rats. Animals were anesthetized with ketamine $(100 \mathrm{mg} / \mathrm{kg}$, i.p., supplemented by injections of $50 \mathrm{mg} / \mathrm{kg}$, i.m.; Imalgène 500 ) and fixed in a conventional stereotaxic apparatus (Horsley Clark apparatus; Unimécanique, Epinay-sur-Seine, France). Body temperature was monitored with a rectal thermometer and maintained at $37^{\circ} \mathrm{C}$ with a homeothermic warming blanket (Harvard Apparatus, Kent, UK).

Single-unit activity of cells located in the striatum (five rats) or in the STN (14 rats) was recorded extracellularly using glass micropipettes (7-10 M $\Omega$ ) filled with $4 \%$ Pontamine sky blue dissolved in a $0.6 \mathrm{~m}$ sodium chloride solution. Action potentials of single neurons were amplified with a differential preamplifier (DAM-5A; World Precision Instruments, Hertfordshire, UK) and displayed on a memory oscilloscope. Spikes were separated from noise using a window discriminator and sampled on-line by a computer connected to a CED 1401 interface (Cambridge Electronic Design, Cambridge, UK). Because striatal cells have very low activity, cortical stimulation was applied continuously during penetration and when a response was observed to one of the cortical stimulation site, the two other stimulation sites were tested.

Peristimulus time histograms (PSTHs) were generated from 50-100 stimulation trials using a binwidth of $1 \mathrm{msec}$ and plotted on a Hewlett Packard plotter. The criterion used to establish the existence of an excitatory response was an increase $>50 \%$ in the number of spikes compared with the prestimulus frequency for at least three consecutive bins. The duration of an inhibitory response corresponds to the time interval during which no spike was observed.

Electrical stimulations of PL-MO areas of the prefrontal cortex (A, $12.5 ; \mathrm{L}, 0.5 ; \mathrm{H}, 3.5 \mathrm{~mm}$ from the cortical surface), the orofacial-forelimb motor cortex (A: 12.5; L: 4.0; H: 1.2), and the auditory cortex (A: 4.7; L: 7; H: 2.0) ipsilateral to the recording sites in the striatum and the STN were made with bipolar coaxial stainless steel electrodes (diameter 400 $\mu \mathrm{m}$, tip-barrel distance, $300 \mu \mathrm{m}$ ) positioned stereotaxically according to the atlas of Paxinos and Watson (1986). Correct positioning of the stimulation site within the orofacial-forelimb motor cortex was achieved by observing the jaw movement elicited by a brief train of pulses. Recording of an evoked potential to an acoustic stimulus (click) ensured correct positioning of the stimulating electrode in the auditory cortex. Electrical stimuli consisted of monopolar pulses of $0.3-0.6$ msec width and $200-600 \mu \mathrm{A}$ intensity delivered at a frequency of 0.5 to $1.4 \mathrm{~Hz}$.

At the end of each recording session, the tip of the stimulating electrodes was marked by an electrical deposit of iron $(15 \mu \mathrm{A}$ anodal, 20 sec) and observed on histological sections after a ferriferrocyanide reaction. The tip of the recording electrode was marked by iontophoretic

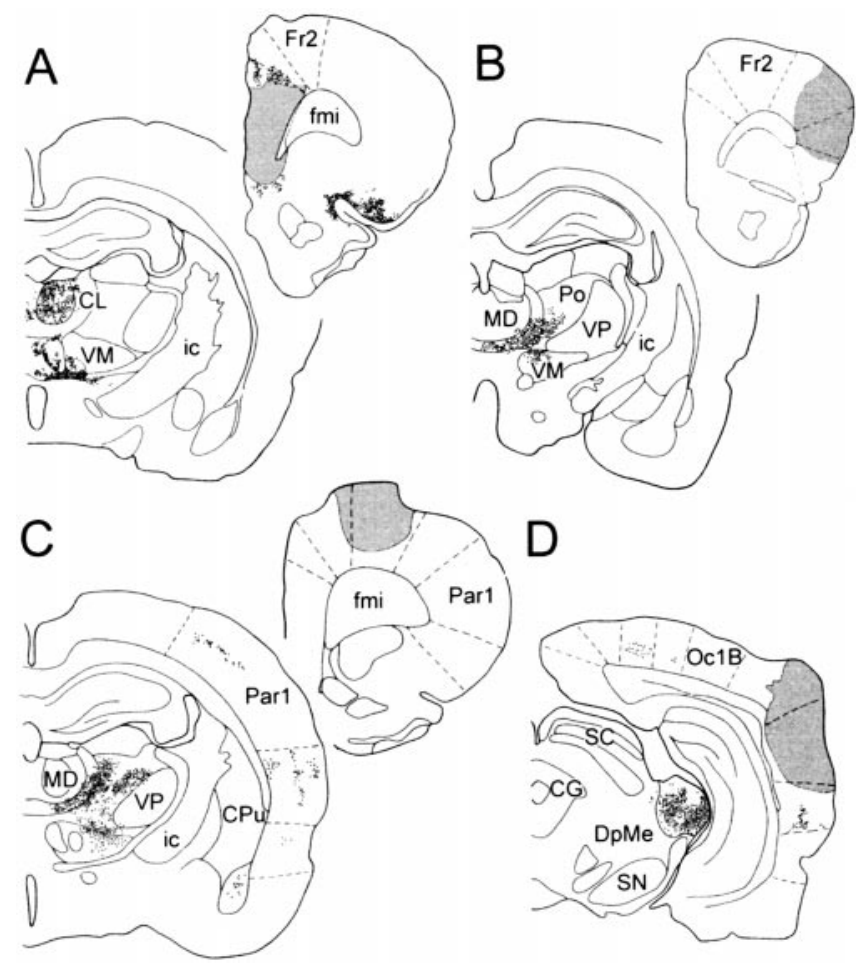

Figure 1. Localization of retrogradely labeled cells in the thalamus after WGA-HRP injection in the PL-MO areas of the prefrontal cortex $(A)$, in the orofacial motor cortex $(B)$, in the forelimb motor cortex $(C)$, and in the auditory cortex $(D)$. Stippled areas, Injection sites. Dots, Retrogradely labeled cells. $C G$, Central gray; $C L$, centrolateral thalamic nucleus; $C P u$, caudate putamen; $D p M e$, deep mesencephalic nuclei; fmi, forceps minor corpus callosum; Fr2, frontal cortex area 2; ic, internal capsule; $M D$, mediodorsal thalamic nucleus; Oc1B, occipital cortex area1; Par1, parietal cortex area 1; $P o$, posterior thalamic nuclear group; $S C$, superior colliculus; $S N$, substantia nigra; $V M$, ventromedial thalamic nucleus; $V P$, ventroposterior thalamic nucleus.

application of Pontamine sky blue ( $8 \mu \mathrm{A}$ cathodal, $20 \mathrm{~min}$ ), which allowed the determination of the position of recorded cells. Brains were removed, fixed in a $10 \%$ formalin solution, and positions of electrodes were microscopically identified on serial frozen sections $(100 \mu \mathrm{m})$ stained with safranin.

\section{RESULTS}

Anatomical organization of projections from prefrontal, motor, and auditory cortical areas within the striatum and the subthalamic nucleus

Single unilateral injections of WGA-HRP were performed in four rats either in the prefrontal, motor, or auditory cortex. In the prefrontal cortex the injection site included the PL-MO areas and extended to the infralimbic area (Fig. $1 A$ ). For the motor cortex, the injection site, in one rat, was centered in the orofacial motor area (Fig. $1 B$ ), and in the other rat the injection site was centered in the forelimb motor area (Fig. $1 C$ ) and overlapped partly the adjacent precentral medial area. In the last rat, the injection site was located in the auditory cortex (Fig. 1D) and overlapped partly the adjacent secondary visual area.

For each injection site, retrogradely labeled cells were observed in distinct thalamic regions known to be related with these cortical areas (Fig. 1). In the case of prefrontal cortex injection, retrogradely labeled cells were observed in the mediodorsal nucleus, the medial part of the ventromedial nucleus and adjacent midline thalamic nuclei, the parataenial nucleus, the paraven- 
tricular nucleus, and the caudomedial part of the parafascicular nucleus. After injection in the orofacial motor cortex, retrogradely labeled cells were located in the central medial nucleus, the paracentral nucleus, the dorsocaudal part of the ventromedial nucleus, the ventral lateral nucleus, and the rostral part of parafascicular nucleus. Retrogradely labeled cells from the forelimb sensorimotor area were located in ventrolateral, central medial, and lateral nuclei, ventral posterolateral nucleus, the ventromedial nucleus except its medial part, and the rostrolateral part of the parafascicular nucleus. After injection in the auditory cortex retrogradely labeled cells were located in the medial geniculate nucleus and the lateral posterior nucleus.

Finally, confirming the lack of direct cortico-cortical connections between the PL-MO areas of the prefrontal cortex, the orofacial-forelimb motor areas, and the auditory cortex, no anterograde or retrograde labeling was observed in these cortical areas.

Within the striatum, the projection fields of anterogradely labeled fibers originating from PL-MO areas, motor (orofacial and forelimb) areas, and auditory cortex are localized in distinct striatal territories (Fig. 2). After WGA-HRP injection in the prefrontal cortex, the projection field of anterogradely labeled fibers occupied the whole rostrocaudal extent of the nucleus accumbens and the adjacent medial part of the dorsal striatum. The projection field of labeled fibers originating from the orofacial motor cortex was located ventrolaterally in the dorsal striatum, and its rostrocaudal extension is restricted to the central part of the structure. After injection in the forelimb motor cortex, anterogradely labeled fibers were distributed in the dorsolateral part of the dorsal striatum and form a rostrocaudal band sparing the most caudal part of the structure. Finally, anterogradely labeled fibers from the auditory cortex were distributed in the most caudal part of the striatum where they form a narrow dorsoventral band adjacent to the external pallidum.

Within the STN, the projection field of anterogradely labeled fibers originating from the PL-MO areas was restricted to the medial third of the structure, whereas projection fields of the orofacial and forelimb motor areas were located more laterally (Fig. 3). Projections from the orofacial motor cortex were distributed in the rostral half of the STN where they occupied the central part of the mediolateral extension of the structure (Fig. 3). The projection field of the fibers originating from the forelimb motor area was located more ventrally and caudally, sparing the medial and the most lateral part of the STN (Fig. 3). Finally, no labeling was observed within the STN after WGA-HRP injection in the auditory cortex.

\section{Characteristics of the responses induced in the striatum by cortical stimulation}

Among the 300 striatal cells tested to electrical stimulation of the prefrontal, the motor, and the auditory cortex (each of these cells being tested to stimulation of the three sites), an excitatory response was observed in 122, 115, and 63 cells, respectively. The mean latencies of the excitatory responses were $11.4 \pm 0.3 \mathrm{msec}$ for the prefrontal cortex, $9.2 \pm 0.2 \mathrm{msec}$ for the motor cortex, and $8.5 \pm 0.4 \mathrm{msec}$ for the auditory cortex stimulation. None of the recorded cells presented response to more than one stimulation site.

Cells responding to electrical stimulation of these cortical regions, observed in 84 from 123 penetrations, were located in distinct striatal territories that did not overlap (Fig. 4). Cells activated from the prefrontal cortex were located medially, in the

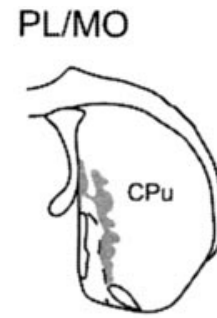

A 8.7
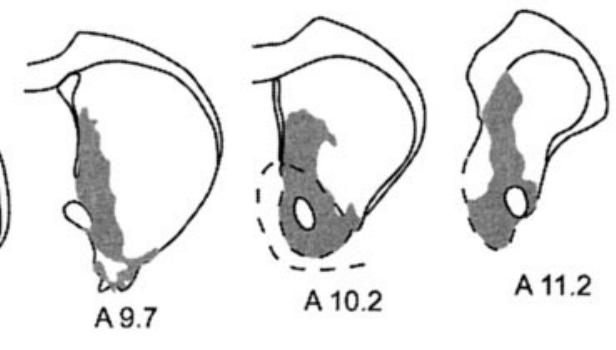

A 11.2

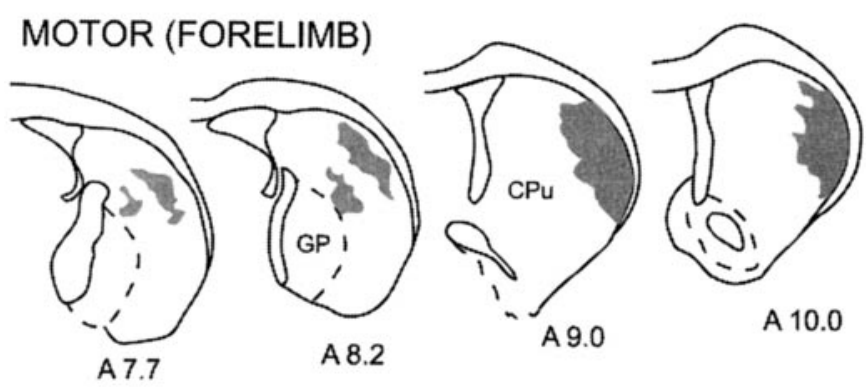

MOTOR (OROFACIAL)
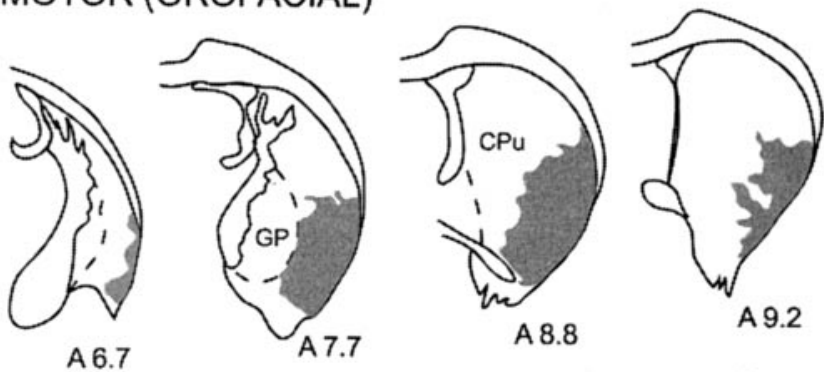

A 6.7
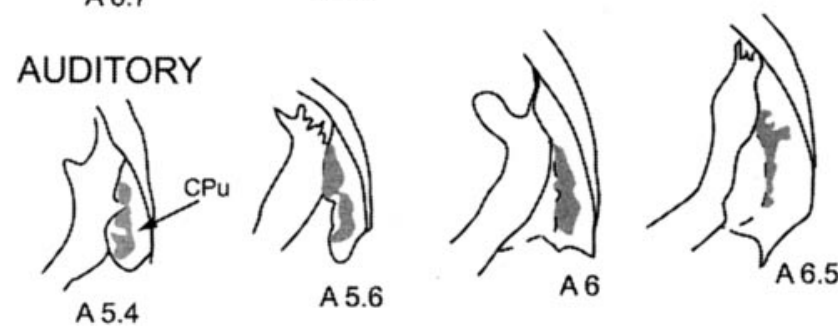

Figure 2. Reconstruction of projection fields of anterogradely labeled fibers within the striatum after WGA-HRP into the PL-MO areas of the prefrontal cortex, the forelimb motor cortex, the orofacial motor cortex, and the auditory cortex. Corresponding injection sites are shown in Figure 1. Projection fields are represented in gray on coronal sections of the striatum. Numbers indicate the corresponding atlas coordinates. $\mathrm{CP} u$, Caudate putamen; GP, globus pallidus.

"core" of the nucleus accumbens and the dorsally adjacent part of the dorsal striatum, whereas those activated from the motor cortex were located in the lateral part of the dorsal striatum. Cells responding to the auditory cortex were found in a medial and caudal striatal region adjacent to the external pallidum. Finally, in the 39 penetrations performed in other regions of the striatum, no responsive cells were observed.

\section{Characteristics of responses induced in the subthalamic nucleus by cortical stimulations}

Responses evoked by electrical stimulations of the PL-MO areas, the orofacial-forelimb motor cortex, and the auditory cortex were investigated in 466 STN cells recorded from 14 rats. Most of these 


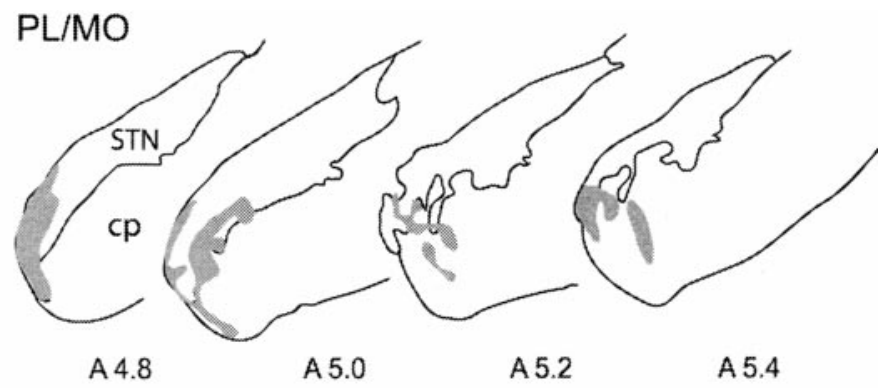

\section{MOTOR (FORELIMB)}

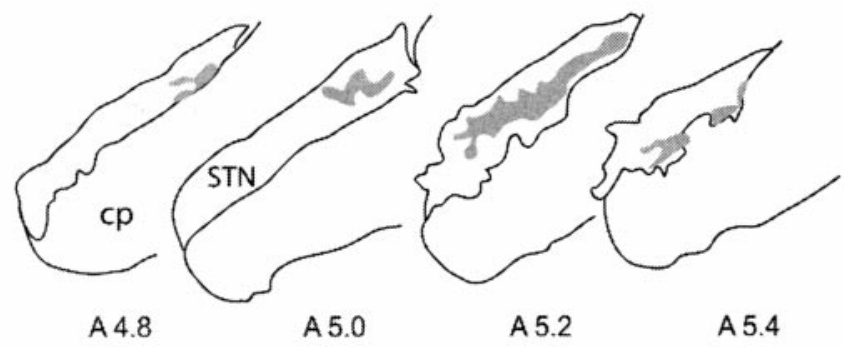

MOTOR (OROFACIAL)

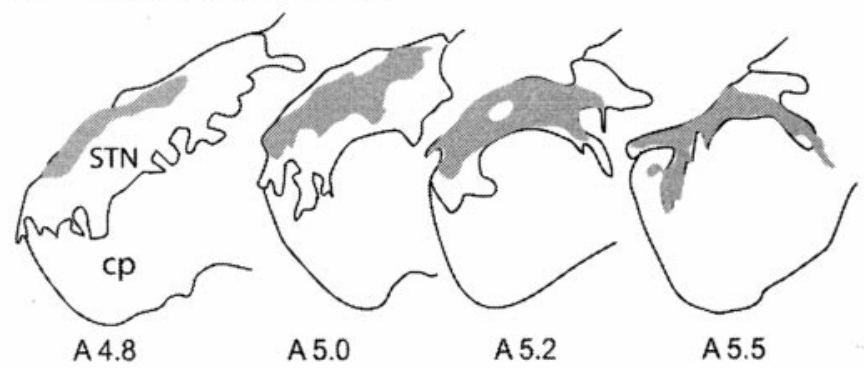

Figure 3. Reconstruction of projection fields of anterogradely labeled fibers within the STN after WGA-HRP injections into the PL-MO areas of the prefrontal cortex, the forelimb motor cortex, and the orofacial motor cortex. Corresponding injection sites are shown in Figure 1. Projection fields are represented in gray on coronal sections. Numbers indicate the corresponding atlas coordinates. $c p$, Cerebral peduncle; STN, subthalamic nucleus.

cells $(n=441)$ presented excitatory responses to the stimulation of at least one of these sites.

\section{Prefrontal cortex}

The electrical stimulation of PL-MO areas evoked excitatory responses in 77 STN cells, but these responses exhibited different patterns (Fig. 5, Table 1). In 26 of these cells, responses consisted of two excitatory peaks with short $(\mathrm{L}=6.8 \pm 0.3 \mathrm{msec})$ and long $(19.2 \pm 0.8 \mathrm{msec})$ latencies to onset, the duration of the late excitatory response being in most cases longer than that of the early excitatory peak (Fig. $5 A, C$ ). In 9 of these 26 cells (35\%), the two excitatory peaks were separated by a brief inhibition $(\mathrm{D}=$ $6.7 \pm 0.8 \mathrm{msec}$ ) (Fig. $5 \mathrm{C})$. A prolonged excitation $(\mathrm{D}=24.8 \pm 1.1$ msec) with an early latency to onset $(\mathrm{L}=8.1 \pm 0.5 \mathrm{msec})$ was observed in 15 cells (Fig. $5 B)$. A single late excitation $(\mathrm{L}=18.5 \pm$ $0.5 \mathrm{msec}$ ) was recorded in $33 \mathrm{STN}$ cells (Fig. $5 D$ ), whereas a single short-duration excitatory peak with an early onset $(\mathrm{L}=7.5 \pm 0.9$ $\mathrm{msec}$ ) was recorded in only three STN cells (Fig. 5E).
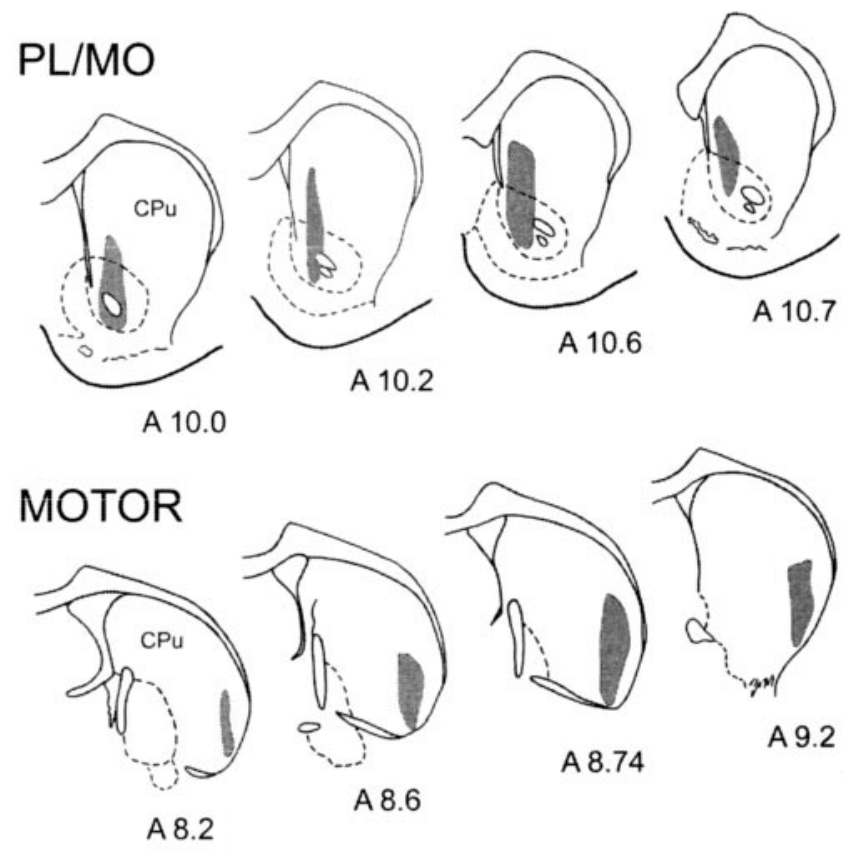

\section{AUDITORY}
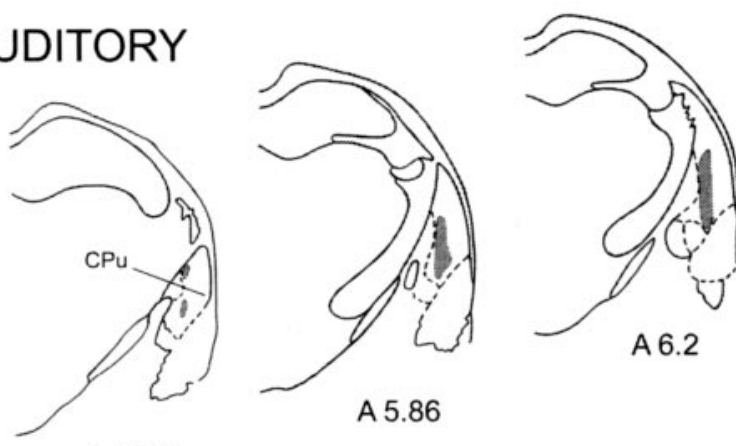

A 5.70
Figure 4. Localization within the striatum of the cells presenting an excitatory response to the stimulation of PL-MO areas of the prefrontal cortex, the orofacial-forelimb areas of the motor cortex, and the auditory cortex. Gray areas delineate the territories where responding cells were located. Numbers indicate the corresponding atlas coordinates. $\mathrm{CPu}$, Caudate putamen.

\section{Motor cortex}

When the electrical stimulation was applied in the orofacialforelimb motor cortex, excitatory responses were recorded in 277 STN cells (Fig. 6, Table 1). In a large proportion of these cells (161 cells), the responses consisted of two excitatory peaks with short $(\mathrm{L}=4.0 \pm 0.1 \mathrm{msec})$ and long $(\mathrm{L}=13.2 \pm 0.3 \mathrm{msec})$ latencies to onset, the duration of the late peak being in most cases longer than that of the early peak (Fig. 6A,C). In 26 of these 161 cells, the two excitatory peaks were separated by a brief inhibition ( $\mathrm{D}=5.5 \pm 0.7 \mathrm{msec}$ ) (Fig. $6 \mathrm{C}$ ). A prolonged excitation $(\mathrm{D}=20.1 \pm 0.6 \mathrm{msec})$ with an early latency to onset $(\mathrm{L}=4.4 \pm$ $0.2 \mathrm{msec}$ ) was observed in 67 cells (Fig. 6B). A single late excitation $(\mathrm{L}=14.2 \pm 0.6 \mathrm{msec})$ was recorded in $39 \mathrm{STN}$ cells (Fig. $6 D)$, whereas an early excitatory peak $(\mathrm{L}=3.5 \pm 0.4 \mathrm{msec})$ of short duration only was recorded in 10 cells (Fig. $6 E$ ).

\section{Auditory cortex}

When the electrical stimulation was made in the auditory cortex, excitatory responses were recorded in 87 STN cells (Fig. 7, Table 

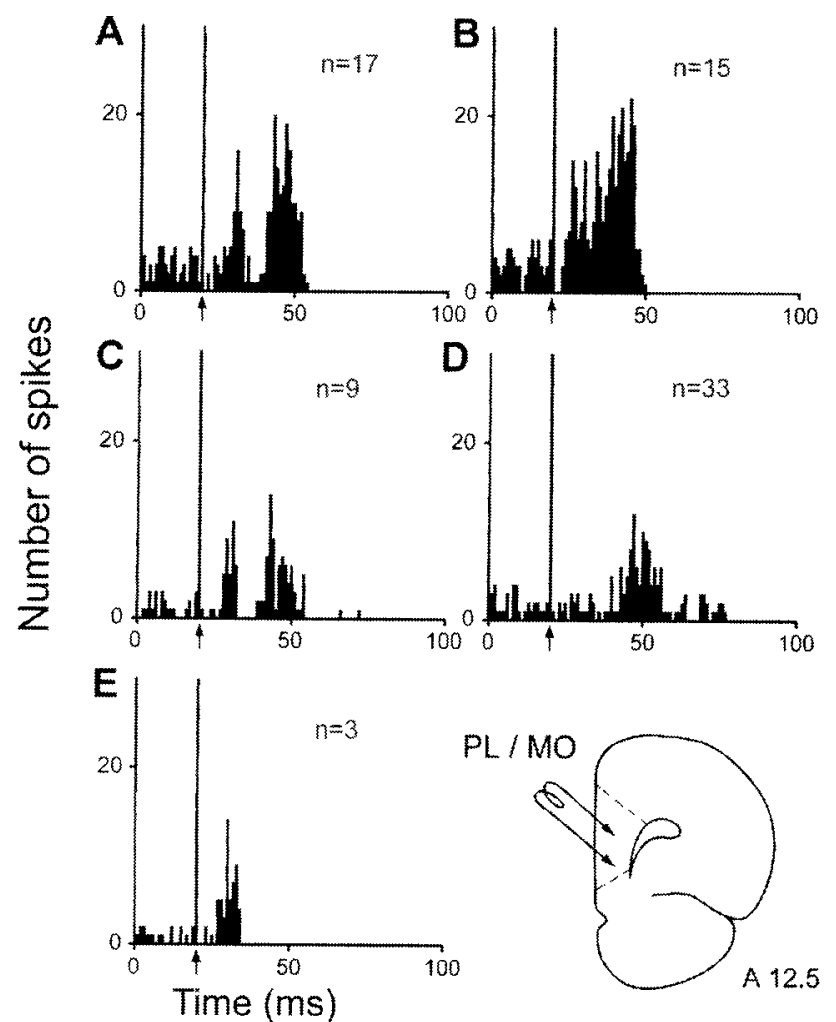

Figure 5. Patterns of responses evoked by PL-MO stimulation in STN cells. $A$, Two excitatory peaks with short- and long-latency onsets; $B$, prolonged excitatory response with a short-latency onset; $C$, two excitatory peaks separated by a brief inhibition; $D$, late excitatory response only; $E$, Early excitatory response only. A-E, Arrows indicate the artifact of stimulation. Peristimulus time histograms were generated from 60 stimulation trials. $n$, Number of cells. Bottom right, Schematic representation of the position of the stimulating electrode in the prefrontal cortex. Number indicates the distance, in millimeters, from the interaural line.

1). In all cases, the response consisted of an excitation with a late onset $(\mathrm{L}=12.2 \pm 0.4 \mathrm{msec})$.

\section{Localization of responding cells}

Cells presenting excitatory responses to the stimulation of either the prefrontal, the motor, or the auditory cortex showed distinct distributions within the STN but with overlapping areas (Fig. $8 A$ ). Cells responding to the PL-MO stimulation were located in the medial part of the STN, whereas most of the cells responding to the orofacial-forelimb motor cortex stimulation were found more laterally. Cells responding to the auditory cortex stimulation were distributed within the ventral part of the STN throughout most of its mediolateral extent, the localization of these cells overlapping partly with that of cells responding to either PL-MO or motor cortex stimulations. Finally, no obvious difference in the topographical distribution of cells responding with different patterns could be observed among the cells that responded to the stimulation of either PL-MO areas or the motor cortex.

\section{Convergent responses induced in single STN cells by stimulations of the prefrontal, motor, and auditory cortices}

Excitatory responses to two distinct cortical stimulation sites were observed in 77 of the 441 responding STN cells (Fig. 8B), however, no cells were found that responded to stimulation of all three sites. Among the $77 \mathrm{STN}$ cells that responded to PL-MO
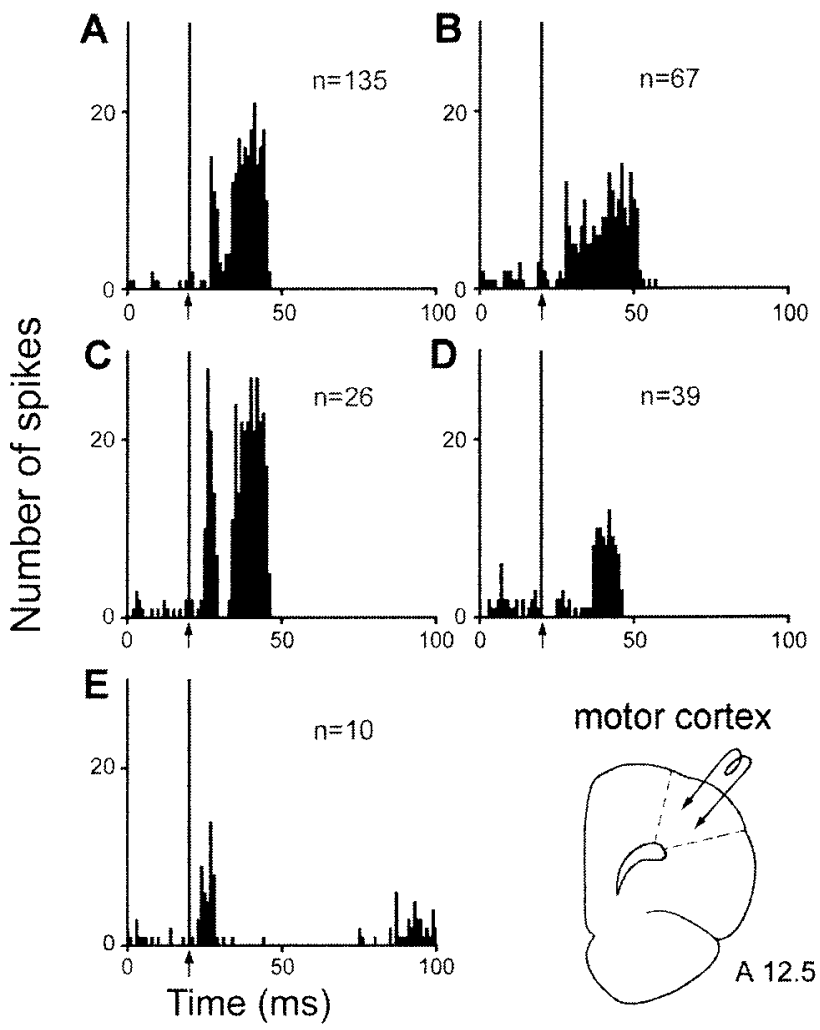

Figure 6. Patterns of responses evoked by motor cortex stimulation in STN cells. $A$, Two excitatory peaks with short- and long-latency onsets; $B$, prolonged excitatory response with a short-latency onset; $C$, two excitatory peaks separated by a brief inhibition; $D$, late excitatory response only; $E$, early excitatory response only. $A-D$, Arrows indicate the artifact of stimulation. Peristimulus time histograms were generated from 60 stimulation trials. $n$, Number of cells. Bottom right, Schematic representation of the position of the stimulation electrode in the motor cortex. Number indicates the distance, in millimeters, from the interaural line.

stimulation and the 277 STN cells that responded to orofacialforelimb motor cortex stimulation, 19 of these cells presented excitatory responses to both stimulation sites (24 and $7 \%$ of cells responding to the PL-MO and orofacial-forelimb motor cortex stimulations, respectively). All these 19 cells presented a late excitation (Fig. 9) that was preceded by an early excitation in 13 neurons. Another population of 10 cells responded to both PL-MO (10/77cells; 12\%) and auditory cortex (10/87; 11\%) stimulations. In all cases, the response consisted of a late excitation (Fig. 10). An additional early response to the prefrontal cortex stimulation was observed in one of these cells. Finally, 48 cells responded to both auditory $(48 / 87 ; 55 \%)$ and motor cortex (48/ $277 ; 17 \%)$ stimulations. All these cells exhibited late excitations (Fig. $11 A, B$ ), and 29 of them presented an additional early excitation to the motor cortex stimulation (Fig. 11A). The distribution of the convergent neurons within the STN is shown in Figure $8 B$.

\section{DISCUSSION}

The present study indicates that the segregation of cortical information originating from the prefrontal, the motor, and the auditory cortex observed in the striatum is only partly maintained in the STN. Indeed, among the overall population of STN recorded cells, a small number of cells responded to both prefrontal and motor cortex stimulations or to prefrontal and auditory cortex, whereas a larger number of cells were activated from both motor and auditory cortices. 
Table 1. Characteristics of the excitatory responses evoked by cortical stimulation in subthalamic cells

\begin{tabular}{|c|c|c|c|c|c|}
\hline \multirow[b]{2}{*}{ Type of response } & \multirow[b]{2}{*}{$\%$ of responding cells } & \multicolumn{2}{|c|}{ Early excitation } & \multicolumn{2}{|c|}{ Late excitation } \\
\hline & & $\mathrm{L}(\mathrm{msec})$ & $\mathrm{D}$ (msec) & $\mathrm{L}(\mathrm{msec})$ & $\mathrm{D}(\mathrm{msec})$ \\
\hline \multicolumn{6}{|l|}{ Prefrontal cortex } \\
\hline Two excitations ${ }^{a}$ & $33.7(n=26)$ & $6.8 \pm 0.3$ & $6.1 \pm 0.5$ & $19.2 \pm 0.8$ & $16.4 \pm 0.9$ \\
\hline One prolonged excitation & $19.5(n=15)$ & $8.1 \pm 0.5$ & $24.8 \pm 1.1$ & & \\
\hline One early excitation & $3.9(n=3)$ & $7.5 \pm 0.9$ & $6.5 \pm 1.0$ & & \\
\hline One late excitation & $42.9(n=33)$ & & & $18.5 \pm 0.5$ & $15.3 \pm 0.7$ \\
\hline \multicolumn{6}{|l|}{ Motor cortex } \\
\hline Two excitations ${ }^{b}$ & $58.1(n=161)$ & $4.0 \pm 0.1$ & $5.0 \pm 0.1$ & $13.2 \pm 0.3$ & $13.5 \pm 0.3$ \\
\hline One prolonged excitation & $24.2(n=67)$ & $4.4 \pm 0.2$ & $20.1 \pm 0.6$ & & \\
\hline One early excitation & $3.6(n=10)$ & $3.5 \pm 0.4$ & $5.8 \pm 1.2$ & & \\
\hline One late excitation & $14.1(n=39)$ & & & $14.2 \pm 0.6$ & $14.5 \pm 1.3$ \\
\hline \multicolumn{6}{|l|}{ Auditory cortex } \\
\hline One late excitation & $100 \quad(n=87)$ & & & $12.2 \pm 0.4$ & $18.6 \pm 0.9$ \\
\hline
\end{tabular}

${ }^{a}$ In 9 of these 26 cells, a short inhibition $(\mathrm{L}=13.5 \pm 0.8 \mathrm{msec} ; \mathrm{D}=6.7 \pm 0.8 \mathrm{msec})$ separated the two excitatory peaks.

${ }^{b}$ In 26 of these 161 cells, a short inhibition $(\mathrm{L}=9.5 \pm 0.4 \mathrm{msec} ; \mathrm{D}=5.5 \pm 0.7 \mathrm{msec})$ separated the two excitatory peaks.

L, Latency; D, duration; $n$, number of cells. Data are presented as mean \pm SEM.

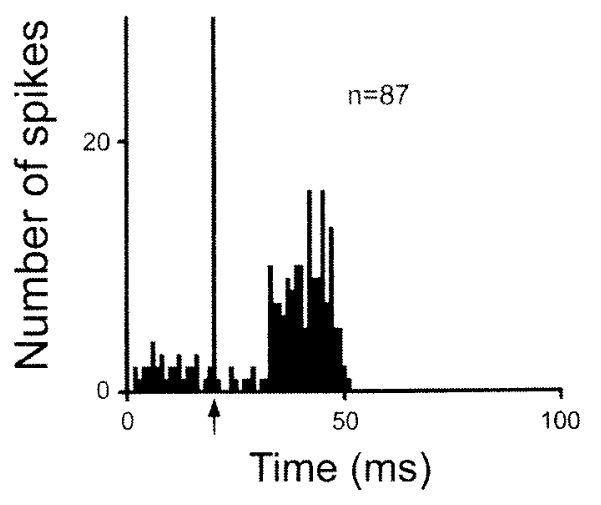

auditory cortex

Figure 7. Pattern of response evoked by auditory cortex stimulation in STN cells. Left, The only pattern of response was an excitation with a late latency. Arrow indicates the artifact of stimulation. Peristimulus time histograms were generated from 60 stimulation trials Right, Schematic representation of the position of the stimulating electrode in the auditory cortex. Number indicates the distance, in millimeters, from the interaural line.

\section{Segregation of inputs from the prefrontal, motor, and auditory cortices in the striatum}

The present data provide further evidence for a segregation in the rat striatum of cortical inputs originating from the PL-MO areas of the prefrontal cortex, the orofacial-forelimb areas of the motor cortex, and the auditory cortex. Indeed, these three functionally distinct cortical regions, which receive inputs from distinct thalamic regions, are not interrelated through direct corticocortical connections (Sesack et al., 1989; Van Eden et al., 1992; present study) and innervate different striatal territories with no overlap. Accordingly, striatal neurons did not receive convergent excitatory inputs from these cortical regions. A topographical organization of the projections from the prefrontal, motor, and auditory cortices similar to that observed in the present study has previously been described (McGeorge and Faull, 1989; Roger and Arnault, 1989; Deniau et al., 1996; Kincaid and Wilson, 1996). However, after injections of WGA-HRP in the rat striatum McGeorge and Faull (1989) suggested that striatal projection fields from prefrontal, motor, and auditory cortex are partly overlapping. This discrepancy with our data is likely attributable
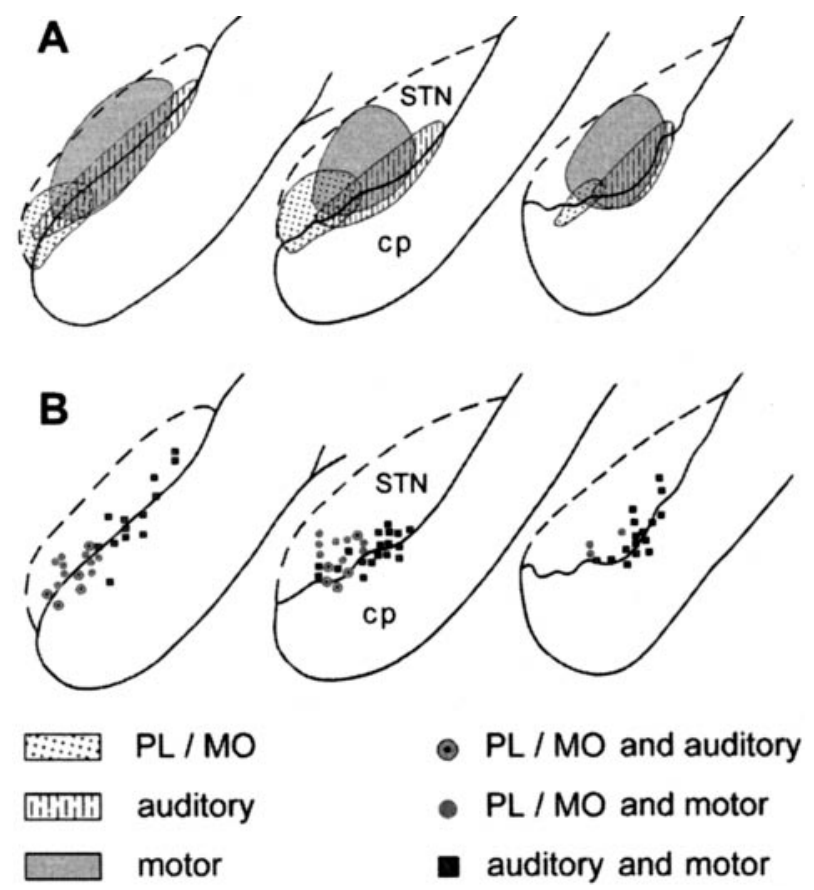

Figure 8. Localization of responding cells within the STN. $A$, Localization of cells presenting excitatory responses to PL-MO, motor, or auditory cortex stimulation. $B$, Localization of cells presenting responses to two stimulation sites: PL-MO and motor cortex, PL-MO and auditory cortex, motor, and auditory cortex. $A, B$, Left to right, Posterior to anterior coronal sections of the STN. $c p$, Cerebral peduncle.

to the location of striatal injection sites that encompassed the specific projection fields of these cortical areas.

\section{The direct and indirect cortico-STN pathways}

The prefrontal and the motor cortices are related to the STN through direct and indirect pathways. In agreement with previous electrophysiological studies (Ryan and Clark, 1991; Fujimoto and Kita, 1993; Kita, 1994; Maurice et al., 1998; Nambu et al., 2000), the responses of STN cells to stimulation of prefrontal or motor cortex consisted of either two excitatory peaks or one prolonged excitation with an early onset. It has been established that the 


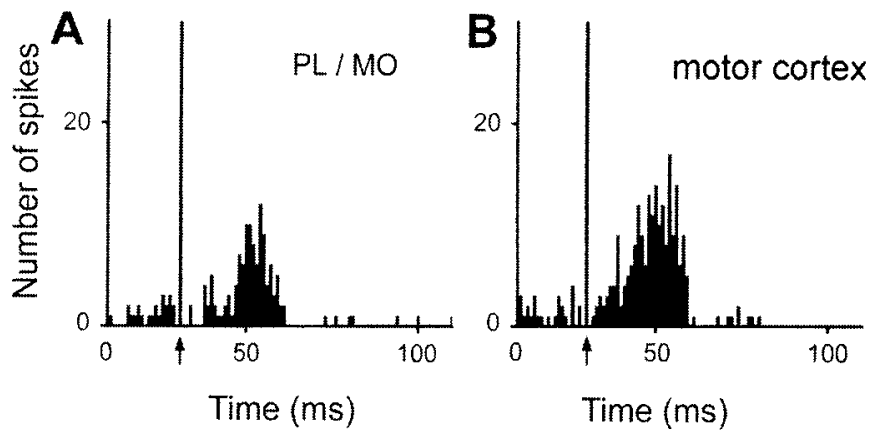

Figure 9. Converging influence of prefrontal and motor cortex in a single STN cell. Responses evoked by PL-MO $(A)$ and motor cortex $(B)$ stimulations in a single STN cell. Arrows indicate the stimulation artifact. Peristimulus time histograms were generated from 60 stimulation trials.

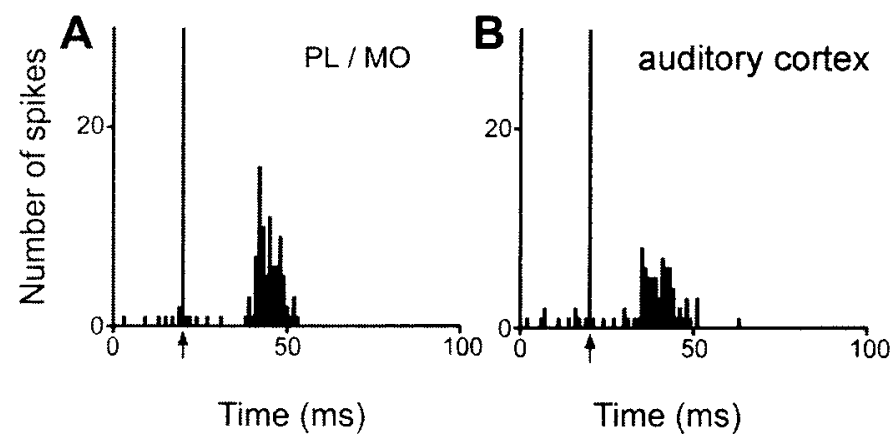

Figure 10. Converging influence of prefrontal and auditory cortex in a single STN cell. Responses evoked by PL-MO $(A)$ and auditory cortex $(B)$ stimulations in a single STN cell. Arrows indicate the stimulation artifact. Peristimulus time histograms were generated from 60 stimulation trials.

early excitatory responses result from the activation of the direct cortico-subthalamic pathway (Kitai and Deniau, 1981), whereas the origin of the late excitatory responses has been controversial. Implication of the indirect striato-pallido-subthalamic circuit has been questioned because the pattern of excitatory responses evoked in the STN by cortical stimulation was not markedly modified after excitotoxic lesions of the striatum or of the external pallidum (Ryan and Clark, 1992; Fujimoto and Kita, 1993; Kita, 1994). Several explanations for these excitatory responses have been proposed: a prolongation of the early excitation caused by activation of the NMDA receptors, the intrinsic membrane properties of STN cells, or finally a spread of excitation through local recurrent collaterals (Kita, 1994). However, the present study shows that stimulation of the auditory cortex, a cortical area that lacks direct projections to the STN, induced only a late excitatory response that was not preceded by an early excitatory peak. This observation is in accordance with recent electrophysiological and pharmacological data in rat and monkey indicating that the late excitatory responses actually result from the activation of the striato-pallido-subthalamic circuit, which operates through a disinhibitory process (Maurice et al., 1998; Nambu et al., 2000).

In the rat, the prefrontal, premotor, and motor cortical areas innervate the STN with a topographical organization (Afshapour, 1985; Canteras et al., 1990; Berendse and Groenewegen, 1991). Accordingly, in the present study anterogradely labeled fibers from the prefrontal cortex were confined to the medial part of the STN, whereas those from the orofacial and forelimb areas of the

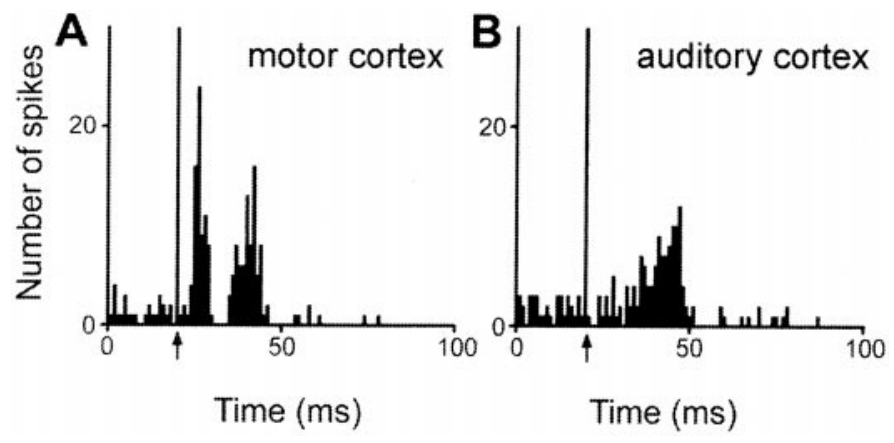

Figure 11. Converging influence of motor and auditory cortex stimulation in a single STN cell. Responses evoked by motor $(A)$ and auditory $(B)$ cortex stimulations in a single STN cell. Arrows indicate the stimulation artifact. Peristimulus time histograms were generated from 60 stimulation trials.

motor cortex were located more laterally. The indirect pathway that connects the whole cerebral cortex to the STN is also topographically organized. Indeed, as previously discussed, the functional mosaic of the cerebral cortex is orderly mapped onto the striatum, and striatal projections to the pallidum as well as pallidal projections to the STN are topographically organized (Haber et al., 1985; Smith et al., 1989, 1998; Groenewegen and Berendse, 1990; Zahm and Brog, 1992; Bevan et al., 1997; Maurice et al., 1997). In agreement with the anatomical organization of the cortico-STN pathways, the cells that presented excitatory responses to stimulation of either prefrontal, motor, or auditory cortex were found in defined territories of the STN. Cells responding to prefrontal cortex stimulation were located medially, and their responses consisted in most cases of an early and a late excitation, indicating a functional convergence of the direct and indirect pathways derived from this cortical region. STN cells responding to stimulation of the motor cortex were located more laterally, and their responses also consisted of an early and a late excitation. Finally, cells responding to the auditory cortex were distributed within a large mediolateral extension of the ventral STN. Their responses consisted only of a late excitation that is attributable to the activation of the indirect pathway.

\section{Patterns of convergence of information from the prefrontal, motor, or auditory cortex in the STN}

Although cells responding to prefrontal, motor, or auditory cortices were located in defined territories of the STN, these territories presented areas of overlap where converging responses to two stimulation sites were observed. Although a large number of cells received converging influence from the auditory cortex and the orofacial-forelimb areas, smaller subpopulations of cells presented excitatory responses to PL-MO and orofacial-forelimb areas or to PL-MO and auditory cortex. It can be excluded that these convergent responses resulted from the activation of cortico-cortical circuits as well as from an integration of cortical information at the level of the striatum. Indeed, PL-MO, orofacial-forelimb, and auditory cortical areas are not related through direct cortico-cortical connections (Sesack et al., 1989; Van Eden et al., 1992; Condé et al., 1995; present study) and, as shown in the present study, no convergent responses were observed in the striatum after stimulation of these areas. Because the STN cells that received a converging influence from the prefrontal and the motor cortex through the direct and indirect pathways were located at the interface of the projection territories of the prefrontal and motor cortex, it can be proposed that the large 
dimension of the dendritic field of STN cells provides an anatomical substrate of this synaptic convergence (Hammond and Yelnik, 1983; Kita et al., 1983; Bevan et al., 1997). Similarly, the convergence of information flow originating from the auditory cortex and from the motor or prefrontal cortex resulted from an integration of cortical information at the level of the STN. Because projections issuing from prefrontal and motor cortex together innervate the entire extent of the STN, they were expected to overlap those originating from other cortical areas that innervate the STN via the indirect circuit. However, it cannot be excluded that integration of striatal information also occurs in the pallidum and thus participates in this convergence.

Finally, in agreement with the existence of a topographical organization in the direct and indirect cortico-STN pathways, the patterns of convergent information flow from the prefrontal, motor and auditory cortices were observed in cells located in defined regions of the STN. Because the STN receives topographically organized afferents from the whole cerebral cortex via the indirect striatopallidal pathway, further patterns of convergence are likely to occur within the STN.

\section{Functional considerations}

Confirming the concept of a parallel organization of basal ganglia circuits in the rat, it was found that information from prefrontal, motor, and auditory cortices remain segregated within the striatum. In addition, the present study revealed, at the level of the STN, defined patterns of convergence of information flow originating from these functionally distinct cortical areas that indicates the existence of an additional level of organization allowing specific interactions between parallel circuits.

It is well established that the cerebral cortex and the basal ganglia are functionally related through multisynaptic loop circuits (Alexander et al., 1986). Within these circuits, the striatum exerts an inhibitory influence on basal ganglia output neurons that results in an activation of their thalamic target cells through a disinhibitory process (Chevalier and Deniau, 1990). This process is considered as the basic mechanism through which signals delivered to the striatum finally increase the excitability of selected regions of the prefrontal and motor cortices and consequently contribute to initiate movements. However, through its prominent excitatory drive on basal ganglia output neurons, the STN counteracts the direct inhibitory influence of the striatum on basal ganglia output neurons. It has been proposed that STN participates in the spatiotemporal shaping of the disinhibitory process and thus contributes to the scaling of movement and suppression of competing motor programs (Mink and Thach, 1993; Nambu et al., 2000). In agreement with this hypothesis, our data reveals that the trans-subthalamic circuits allow specific interactions between information from functionally distinct cortical areas. Understanding the physiological significance of such interactions in the selection of behaviors is necessary to determine how the cortical information flow processed through the trans-subthalamic and the trans-striatal pathways interacts at the level of basal ganglia output neurons.

\section{REFERENCES}

Afshapour S (1985) Topographical projections of the cerebral cortex to the subthalamic nucleus. J Comp Neurol 236:14-28.

Albin RL, Young AB, Penney JB (1989) The functional anatomy of basal ganglia disorders. Trends Neurosci 12:366-375.

Alexander GE, DeLong MR, Strick PL (1986) Parallel organization of functionally segregated circuits linking basal ganglia and cortex. Annu Rev Neurosci 9:357-381.

Berendse HW, Groenewegen HJ (1991) The connections of the medial part of the subthalamic nucleus in the rat: evidence for a parallel organization. In: The basal ganglia III (Bernardi G, Carpenter MB, Di Chiara G, Morelli M, Stanzione P, eds), pp 89-98. New York: Plenum.

Bevan MD, Clark NP, Bolam JP (1997) Synaptic integration of functionally diverse pallidal information in the entopeduncular nucleus and subthalamic nucleus in the rat. J Neurosci 17:308-324.

Canteras NS, Shammah-Lagnado SJ, Sila BA, Ricardo JA (1990) Afferent connection of the subthalamic nucleus: a combined retrograde and anterograde horseradish peroxidase study in the rat. Brain Res 513:43-59.

Chevalier G, Deniau JM (1990) Disinhibition as a basic process in the expression of striatal functions. Trends Neurosci 10:277-280.

Condé F, Maire-Lepoivre E, Audinat E, Crépel F (1995) Afferent connections of the medial frontal cortex of the rat. II Cortical and subcortical afferents. J Comp Neurol 352:567-593.

Deniau JM, Thierry AM (1997) Anatomical segregation of information processing in the rat substantia nigra pars reticulata. In: The basal ganglia and new surgical approaches for Parkinson's disease, Vol 74, Advances in neurology (Obeso JA, DeL ong MR, Ohye C, Marsden CD eds), pp 83-96. Philadelphia: Lippincott-Raven.

Deniau JM, Ménétrey A, Charpier S (1996) The lamellar organization of the rat substantia nigra pars reticulata: segregated patterns of striatal afferents and relationship to the topography of corticostriatal projections. Neuroscience 73:761-781.

Flaherty AW, Graybiel AM (1991) Corticostriatal transformations in the primate somatosensory system. Projections from physiologically mapped body-part representations. J Neurophysiol 66:1249-1263.

Fujimoto K, Kita H (1993) Response characteristics of subthalamic neurons to the stimulation of the sensorimotor cortex in the rat. Brain Res 609:185-192.

Groenewegen HG, Berendse HV (1990) Connections of the subthalamic nucleus with ventral striatopallidal parts of the basal ganglia in the rat. J Comp Neurol 294:607-622.

Groenewegen HJ, Berendse HV (1994) Anatomical relationships between the prefrontal cortex and the basal ganglia in the rat. In: Motor and cognitive functions of the prefrontal cortex (Thierry AM, Glowinski J, Goldman-Rakic P, Christen Y, eds), pp 51-77. Berlin: Springer.

Haber SN, Groenewegen HJ, Grove EA, Nauta WJH (1985) Efferent connections of the ventral pallidum: evidence of a dual striatopallidofugal pathway. J Comp Neurol 235:322-335.

Hammond C, Yelnik J (1983) Intracellular labelling of rat subthalamic neurones with horseradish peroxidase: computer analysis of dendrites and characterization of axon arborization. Neuroscience 8:781-790.

Joel D, Weiner I (1997) The connections of the primate subthalamic nucleus: indirect pathways and the open-interconnected scheme of basal ganglia-thalamocortical circuitry. Brain Res Rev 23:62-78.

Kincaid AE, Wilson CJ (1996) Corticostriatal innervation of the patch and matrix in the rat striatum. J Comp Neurol 374:578-592.

Kita H (1994) Physiology of two disynaptic pathways from the sensorimotor cortex to the basal ganglia output nuclei. In: The basal ganglia IV (Percheron G, McKenzie JS, Féger J, eds), pp 263-276. New York: Plenum.

Kita H, Chang HT, Kitai ST (1983) The morphology of intracellularly labelled rat subthalamic neurons: a light microscopic analysis. J Comp Neurol 215:245-257.

Kitai ST, Deniau JM (1981) Cortical inputs to the subthalamus: intracellular analysis. Brain Res 214:411-415.

Kitai ST, Kita H (1987) Anatomy and physiology of subthalamic nucleus: a driving force of the basal ganglia. In: The basal ganglia II (Carpenter MB, Jayaraman A, eds) pp 357-373. New York: Plenum.

Kitano H, Tanibuchi I, Jinnai K (1998) The distribution of neurons in the substantia nigra pars reticulata with input from the motor, premotor and prefrontal areas of the cerebral cortex in monkeys. Brain Res $784: 228-238$

Maurice N, Deniau JM, Ménétrey A, Glowinski J, Thierry AM (1997) Position of the ventral pallidum in the rat prefrontal cortex-basal ganglia circuit. Neuroscience 80:523-534.

Maurice N, Deniau JM, Glowinski J, Thierry AM (1998) Relationship between the prefrontal cortex and the basal ganglia in the rat: physiology of the corticosubthalamic circuits. J Neurosci 18:9539-9546.

Maurice N, Deniau JM, Glowinski J, Thierry AM (1999) Relationships between the prefrontal cortex and the basel ganglia in the rat: physiology of the cortico-nigral circuits. J Neurosci 19:4674-4681.

McGeorge AJ, Faull RLM (1989) The organization of the projection from the cerebral cortex to the striatum in the rat. Neuroscience 29:503-537.

Mesulam MM (1978) Tetramethyl benzidine horseradish peroxidase neurochemistry: a non-carcinogenic blue reaction product with superior sensitivity for visualizing neural afferents and efferents. J Histochem Cytochem 26:106-117.

Mink JW, Thach WT (1993) Basal ganglia intrinsic circuits and their role in behavior. Curr Opin Neurobiol 3:950-957.

Nambu A, Takada M, Inase M, Tokuno H (1996) Dual somatotopical representations in the primate subthalamic nucleus: evidence for or- 
dered but reversed body-map transformations from the primary motor cortex and the supplementary motor area. J Neurosci 16:2671-2683.

Nambu A, Tokuno H, Hamada I, Kita H, Imanishi M, Akazawa T, Ikeuchi Y, Hasegawa N (2000) Excitatory cortical inputs to pallidal neurons via the subthalamic nucleus in the monkey. J Neurophysiol 84:289-300.

Paxinos G, Watson C (1986) The rat brain in stereotaxic coordinates, Ed 2. New York: Academic.

Roger M, Arnault P (1989) Anatomical study of the connections of the primary auditory area in the rat. J Comp Neurol 287:339-356.

Ryan LJ, Clark KB (1991) The role of the subthalamic nucleus in the response of globus pallidus neurons to stimulation of the prelimbic and agranular frontal cortices in rats. Exp Brain Res 86:641-651.

Ryan LJ, Clark KB (1992) Alteration of neuronal responses in the subthalamic nucleus following globus pallidus and neostriatal lesions in rats. Brain Res Bull 29:319-327.

Sesack SR, Deutch AY, Roth RH, Bunney BS (1989) Topographical organization of the efferent projections of the medial prefrontal cortex in the rat: an anterograde tract-tracing study with Phaseolus vulgaris leucoagglutinin. J Comp Neurol 290:213-242.

Smith Y, Bolam JP, von Krosick M (1989) Topographical and synaptic organization of the GABA-containing pallidosubthalamic projection in the rat. Eur J Neurosci 2:500-511.

Smith Y, Bevan MD, Shink E, Bolam JP (1998) Microcircuitry of the direct and indirect pathways of the basal ganglia. Neuroscience 86: 353-387.

Van Eden CG, Lamme VAF, Uylings HBM (1992) Heterotopic cortical afferents to the medial prefrontal cortex in the rat. A combined retrograde and anterograde tracer study. Eur J Neurosci 4:77-97.

Yeterian EH, Van Hoesen GW (1978) Cortico-striate projections in the rhesus monkey: the organization of certain cortico-caudate connections. Brain Res 139:43-63.

Zahm DS, Brog JS (1992) On the significance of subterritories in the "accumbens" part of the ventral striatum. Neuroscience 50:751-767. 